\title{
Pyrite nanoparticles as a Fenton-like reagent for in situ remediation of organic pollutants
}

\author{
Carolina Gil-Lozano ${ }^{* 1}$, Elisabeth Losa-Adams ${ }^{1}$, Alfonso F.-Dávila ${ }^{2}$ \\ and Luis Gago-Duport ${ }^{1}$
}

\author{
Full Research Paper \\ Address: \\ ${ }^{1}$ Departamento de Geociencias Marinas, Universidad de Vigo, \\ Lagoas Marcosende, 36310-Vigo, Spain and ${ }^{2}$ Carl Sagan Center, \\ SETI Institute, 189 Bernardo Avenue, Suite 100, Mountain View, CA \\ 94043, USA \\ Email: \\ Carolina Gil-Lozano* - karolina_gil@uvigo.es \\ * Corresponding author \\ Keywords: \\ copper phthalocyanine; Fenton-like reagent; hydrogen peroxide; \\ nanoparticles; pyrite
}

Open Access

Beilstein J. Nanotechnol. 2014, 5, 855-864. doi:10.3762/bjnano.5.97

Received: 15 February 2014

Accepted: 15 May 2014

Published: 16 June 2014

This article is part of the Thematic Series "Nanomanipulation and environmental nanotechnology".

Guest Editor: E. Gnecco

(C) 2014 Gil-Lozano et al; licensee Beilstein-Institut. License and terms: see end of document.

\begin{abstract}
The Fenton reaction is the most widely used advanced oxidation process (AOP) for wastewater treatment. This study reports on the use of pyrite nanoparticles and microparticles as Fenton reagents for the oxidative degradation of copper phthalocyanine (CuPc) as a representative contaminant. Upon oxidative dissolution in water, pyrite $\left(\mathrm{FeS}_{2}\right)$ particles can generate $\mathrm{H}_{2} \mathrm{O}_{2}$ at their surface while simultaneously promoting recycling of $\mathrm{Fe}^{3+}$ into $\mathrm{Fe}^{2+}$ and vice versa. Pyrite nanoparticles were synthesized by the hot injection method. The use of a high concentration of precursors gave individual nanoparticles (diameter: $20 \mathrm{~nm}$ ) with broader crystallinity at the outer interfaces, providing a greater number of surface defects, which is advantageous for generating $\mathrm{H}_{2} \mathrm{O}_{2}$. Batch reactions were run to monitor the kinetics of CuPc degradation in real time and the amount of $\mathrm{H}_{2} \mathrm{O}_{2}$. A markedly greater degradation of $\mathrm{CuPc}$ was achieved with nanoparticles as compared to microparticles: at low loadings $(0.08 \mathrm{mg} / \mathrm{L})$ and $20 \mathrm{~h}$ reaction time, the former enabled $60 \% \mathrm{CuPc}$ removal, whereas the latter enabled only $7 \%$ removal. These results confirm that the use of low concentrations of synthetic nanoparticles can be a cost effective alternative to conventional Fenton procedures for use in wastewater treatment, avoiding the potential risks caused by the release of heavy metals upon dissolution of natural pyrites.
\end{abstract}

\section{Introduction}

There has been growing interest in nanomaterials for green environmental remediation. For example, catalytically active synthetic nanoparticles inspired by natural minerals have been combined with in situ advanced oxidation processes (AOPs) as a potential strategy to remediate contaminants [1-3]. These
AOPs generate hydroxyl radicals $\left(\mathrm{OH}^{*}\right)$ that trigger the formation of other reactive intermediates (e.g., $\mathrm{HO}_{2}{ }^{\bullet}$ and $\mathrm{O}_{2}{ }^{--}$). Due to their high oxidation potential $\left(E^{0}=2.8 \mathrm{~V}\right)$, hydroxyl radicals attack most organic pollutants with rate constants in the order of $10^{6}$ to $10^{9} \mathrm{M}^{-1} \cdot \mathrm{s}^{-1}[4,5]$. In practice, the formation of $\mathrm{OH}^{\bullet}$ to 
degrade organic compounds involves the iron $\left(\mathrm{Fe}^{2+}\right.$ and $\left.\mathrm{Fe}^{3+}\right)$ catalysed decomposition of $\mathrm{H}_{2} \mathrm{O}_{2}$; this transformation is known as the Fenton reaction [6]. A major drawback of conventional Fenton chemistry for wastewater treatment is that it requires a continuous supply of $\mathrm{H}_{2} \mathrm{O}_{2}$ under strict $\mathrm{pH}$ control, to limit the precipitation of iron oxyhydroxides. However, this control makes the process difficult and cost expensive.

Green nanotechnology can be used in various industrial and in situ remediation processes and can be an effective option for wastewater treatment. Several studies have recently reported the capacity of mineral suspensions (e.g., silicates, oxides and sulfides) to continuously generate $\mathrm{H}_{2} \mathrm{O}_{2}$ at surface defect sites [7-14]. Since the catalytic performance of the particles depends on the surface area-to-volume ratio (i.e., better performance is enabled by higher ratios), nanoparticles are typically expected to be more reactive than microparticles. Following this logic, and given the fact that pyrite microparticles have already been explored in Fenton chemistry [15], we sought to explore pyrite nanoparticles as heterogeneous catalysts for Fenton-like systems. Pyrite, the most abundant iron sulfide in the crust of Earth, releases $\mathrm{Fe}^{2+}$ and $\mathrm{H}^{+}$upon oxidative dissolution. As such, it has been used with $\mathrm{H}_{2} \mathrm{O}_{2}$ as a Fenton catalyst for the degradation of several organic pollutants, including trinitrotoluene, carbon tetrachloride and diclofenac [16-19]. Several recent studies have reported that pyrite can spontaneously produce $\mathrm{H}_{2} \mathrm{O}_{2}$ via catalytic dissociation of $\mathrm{O}_{2}$ and $\mathrm{H}_{2} \mathrm{O}$ with iron surface sites $[7,8,10,12-14]$. Albeit the use of pyrite alone as Fenton reagent (i.e., without externally added $\mathrm{H}_{2} \mathrm{O}_{2}$ ) has been demonstrated for lactate degradation [15], this approach remains poorly studied and, to the best of our knowledge, has never been used to remove dyes from textile wastewater.

In this work, we compared synthetic pyrite nanoparticles to naturally derived pyrite microparticles for their efficiency in the oxidative degradation of copper phthalocyanine $(\mathrm{CuPc})$, a representative dye that has a metallic ring structure. Phthalocyanines are widely used in the textile industry and can provoke carcinogenesis. However, removal of metallocyanines is difficult because of their resistance towards oxidative degradation as well as their low biodegradability. To this end, we performed real time experiments to determine the degradation rate of $\mathrm{CuPc}$ induced by $\mathrm{H}_{2} \mathrm{O}_{2}$ generated at the surface of the pyrite nanoparticles or microparticles, using UV-vis adsorption spectroscopy and $\mathrm{H}_{2} \mathrm{O}_{2}$ sensors.

\section{Results}

\section{Structural aspects of the pyrite nanoparticles}

The pyrite nanoparticles were analyzed at bulk level by XRD to evaluate the possible formation of secondary phases (Figure 1). As shown in the XRD pattern, the only observable Bragg reflec- tions correspond to lattice planes of the cubic structure of pyrite (JCPDS card no. 42-1340). A moderate amount of background is also present in the pattern, where it is especially marked at the tail of the intensity distribution. This type of broadening is a characteristic indicator that coherent X-ray diffraction is occurring in finite-size domains (e.g., sub-grains). The average size of the crystalline domains (as calculated by Rietveld analysis) was $20 \mathrm{~nm}$, which is consistent with the HR-TEM observation of the individual particles.

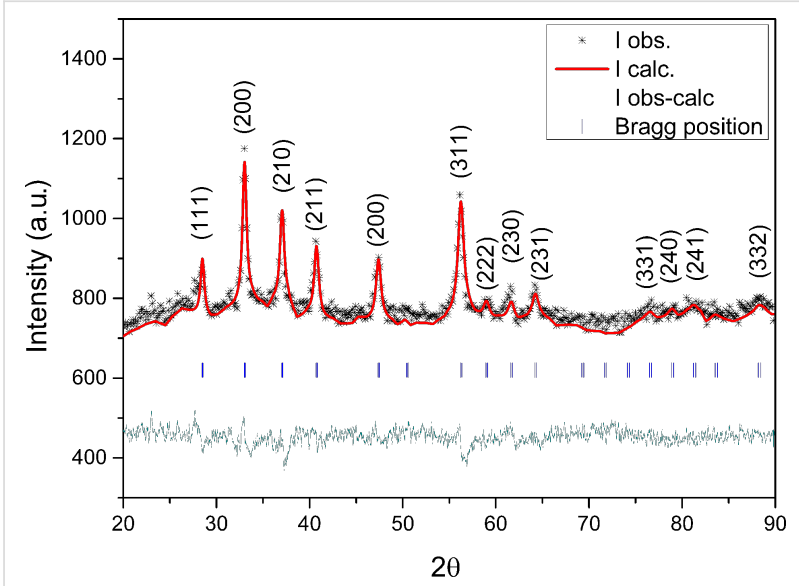

Figure 1: XRD pattern of the nanoparticles, indicating that pyrite was the only crystalline phase resulting from the synthesis. Rietveld analysis of the reflection broadening gave an average crystallite size of $20 \mathrm{~nm}$.

The TEM micrographs of the nanoparticles are shown in Figure 2. The upper left panel (Figure 2a) corresponds to a lowmagnification image that shows the typical arrangement of nanocrystals obtained in our syntheses. The nanoparticles tended to aggregate, forming polydisperse clusters of rounded particles ranging in size from $20 \mathrm{~nm}$ (individual nanoparticle) to $150 \mathrm{~nm}$ (largest cluster). At the initial stages of the process, the clusters were polycrystalline, as indicated by the SAED pattern (Figure 2b). However, as crystallization progressed, some of the particles tended to reorganize, giving rise to single-crystal domains that extended to several particles. This feature is observable in the HR-TEM image (Figure 2c), in which two particles have self-assembled and their lattice fringes, corresponding to the (200) planes, exhibit coherent interference domains. This fact is also confirmed by the FFT superposition of the two particles (inset), which reveals that the diffraction spots have identical orientation. Interestingly, individual particles were surrounded by an amorphous layer (thickness: ca. 2 to $3 \mathrm{~nm}$ ), suggesting that crystallization had begun upon nucleation of an amorphous precursor and subsequently followed some type of structural reorganization associated with highenergy surfaces between adjacent particles [20-22]. Similar textures have been observed in other syntheses, especially when 


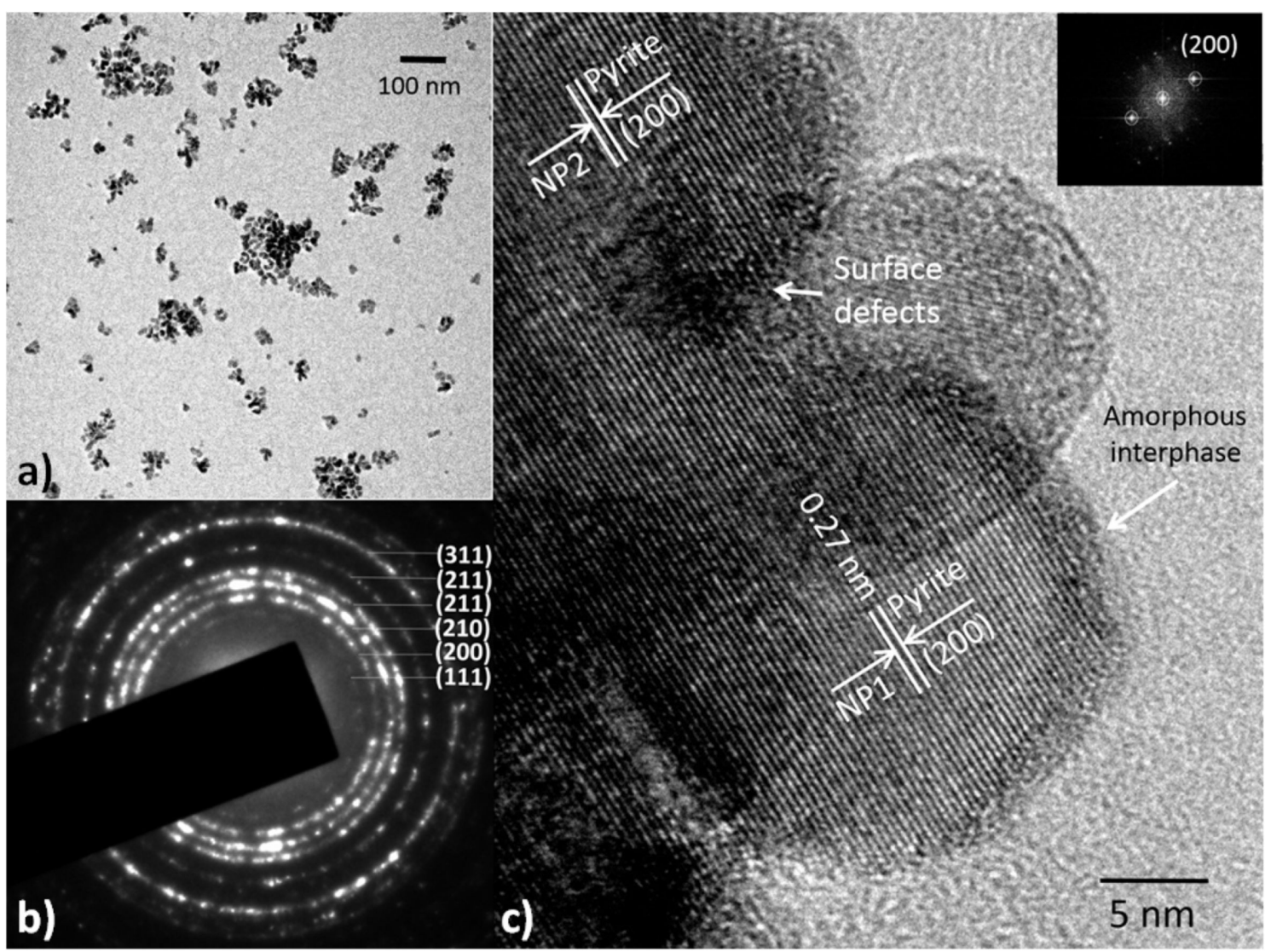

Figure 2: a) TEM image of the typical distribution of the nanoparticles, comprising polycrystalline aggregates of pyrite. b) SAED pattern of the nanoparticles. c) HR-TEM image showing the structure of the nanoparticles. Individual nanoparticles tended to self-assemble, thereby forming finitesize crystalline domains extended over several particles. The surface of the nanoparticles always appeared to be surrounded by an amorphous layer.

high concentrations of precursors were employed [23-26]. This factor can be a limitation when high crystallinity is required; in such cases, use of low reagent concentrations or surfactants is often required to keep the particles apart. However, for the purposes of our work, the formation of interphases with numerous defects is advantageous, since the generation of $\mathrm{H}_{2} \mathrm{O}_{2}$ relies precisely on the presence of these defect sites.

\section{Kinetics of $\mathrm{H}_{2} \mathrm{O}_{2}$ generation and CuPc decol- oration \\ Effect of pyrite particle surface area on reactivity}

In order to evaluate the influence of the pyrite particle surface area on the amount of $\mathrm{H}_{2} \mathrm{O}_{2}$ generated and on the dye decoloration (degradation) pathway, we performed kinetic experiments with dispersions of pyrite nanoparticles or microparticles (Figure 3, see section Experimental below). The same initial particle loading $(0.08 \mathrm{~g} / \mathrm{L})$ and dye concentration $(0.1 \mathrm{mg} / \mathrm{L})$ were used. When nanoparticles were employed (Figure 3, curve a), the amount of $\mathrm{H}_{2} \mathrm{O}_{2}$ detected by the sensor oscillated, rose to a maximum value of $1.4 \mu \mathrm{M}$, rapidly decreased to zero and finally, plateaued at $0.2 \mu \mathrm{M}$ within ca. $10 \mathrm{~h}$. The oscillatory trend and the rapid decrease in $\mathrm{H}_{2} \mathrm{O}_{2}$ levels suggest that with the nanoparticles, nearly all the generated $\mathrm{H}_{2} \mathrm{O}_{2}$ had been immediately transformed into less stable free radical species, in a process catalyzed by the $\mathrm{Fe}^{2+}$ ions released during their rapid dissolution. However, the microparticles gave vastly distinct results: the $\mathrm{H}_{2} \mathrm{O}_{2}$ was generated much more slowly, and gradually accumulated in solution (Figure 3 , curve b). This observation suggests a less efficient conversion of $\mathrm{H}_{2} \mathrm{O}_{2}$ into free radicals, which would be consistent with a lower rate of iron delivery to solution than in the case of the nanoparticles. This hypothesis is consistent with PHREEQC calculations [27] of the total iron $\left[\mathrm{Fe}^{2+}+\mathrm{Fe}^{3+}\right]$ released (Figure 3, inset) in each case, using the rate expression of Williamson and Rimstidt [28]. The reactive surface was estimated by the geometrical model assuming cubes of $20 \mathrm{~nm}$ for nanoparticles and $1.4 \mu \mathrm{m}$ for microparticles.

The degradation efficiency in each case is shown in Figure 4. During the start-up period (about 5 to $6 \mathrm{~h}$ ), decomposition was very similar in each reaction, with a rate constant of $k_{1}=0.004 \mathrm{~h}^{-1}$. Afterwards, the rate constant in the nanoparticle 


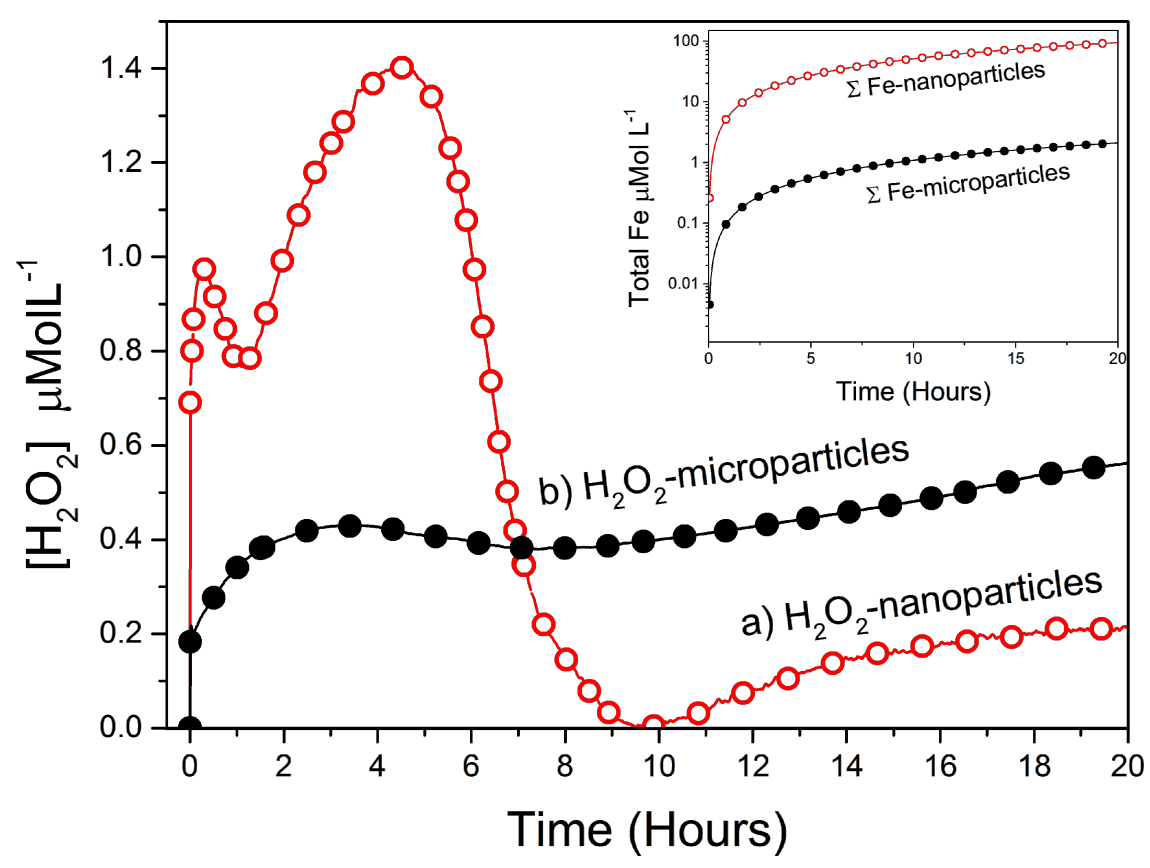

Figure 3: Plot of $\mathrm{H}_{2} \mathrm{O}_{2}$ concentration over time for suspensions of: a) pyrite nanoparticles or b) pyrite microparticles, at loadings of $0.08 \mathrm{~g} / \mathrm{L}$. Inset: Plot of PHREEQC calculations of total iron $\left[\mathrm{Fe}^{2+}+\mathrm{Fe}^{3+}\right]$ delivered in each case, assuming cubes of $20 \mathrm{~nm}$ for nanoparticles and $1.4 \mu \mathrm{m}$ for microparticles.

reaction increased to $k_{2}=0.07 \mathrm{~h}^{-1}$, which in terms of degradation efficiency $\left(\left[1-\left(C / C_{0}\right)\right] \times 100 \%\right)$ represents a final value ca. 8 times higher than in the microparticle experiments.

\section{Effect of pyrite particle loading and phthalocyanine concentration}

The influence of the initial mass of pyrite on the CuPc degradation was assessed by performing experiments with nanoparti-

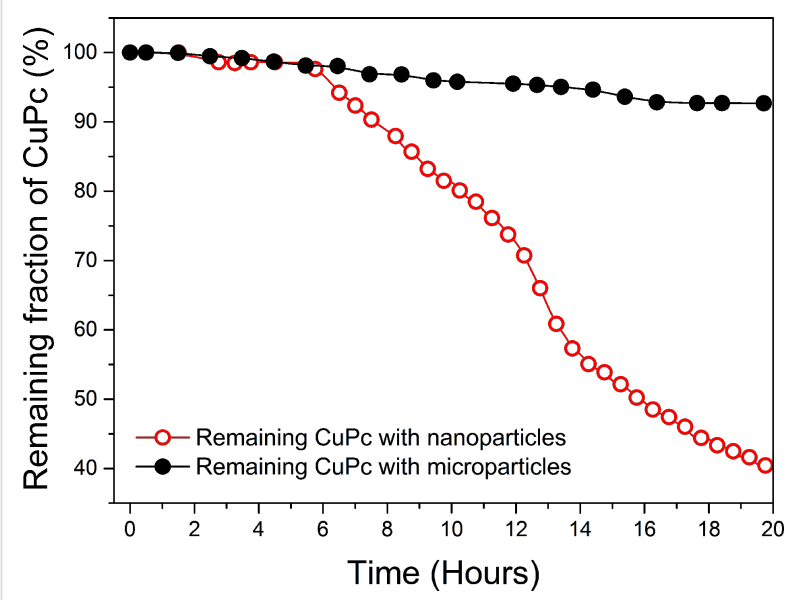

Figure 4: Rate of CuPc decoloration (initial concentration: $0.1 \mathrm{mg} / \mathrm{L}$ ) in suspensions of pyrite nanoparticles (average size: $20 \mathrm{~nm}$; red circles) or microparticles (average size: $1.4 \mu \mathrm{m}$; black circles), at loadings of $0.08 \mathrm{~g} / \mathrm{L}$. cles at three different loadings. As shown in Figure 5, even small differences on pyrite loadings prompted changes in the degradation efficiency of $\mathrm{CuPc}$, with the higher loading corresponding to a faster CuPc decomposition $\left(k_{1}=0.07 \mathrm{~h}^{-1}\right.$ at $0.08 \mathrm{~g} / \mathrm{L}, k_{2}=0.04 \mathrm{~h}^{-1}$ at $0.04 \mathrm{~g} / \mathrm{L}$ and $k_{3}=0.003 \mathrm{~h}^{-1}$ at $0.02 \mathrm{~g} / \mathrm{L}$ ) and consequently leading to more efficient degradation (the higher loading experiment was about 8 times more efficient).

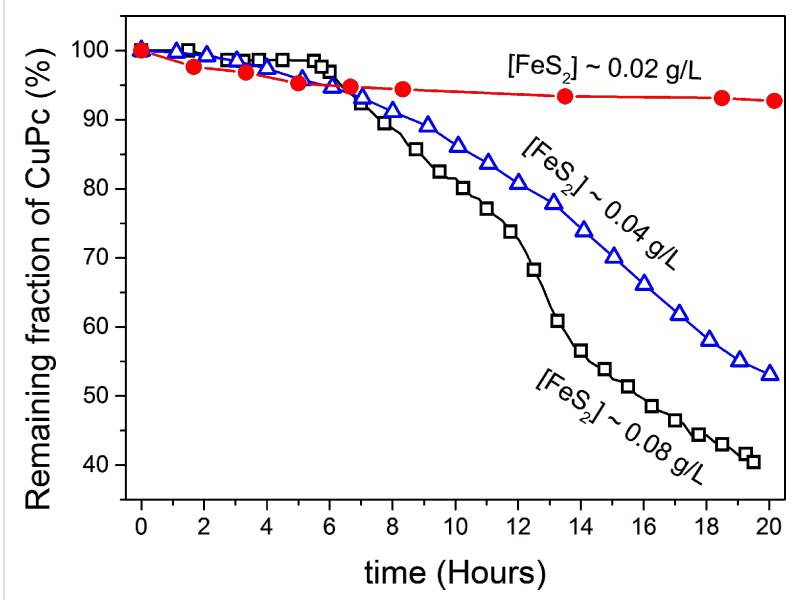

Figure 5: Effect of pyrite nanoparticle loading on the rate of CuPc decoloration. $\left([\mathrm{CuPc}]_{0}=0.1 \mathrm{mg} / \mathrm{L}\right.$, loadings values are marked in the curves). 
We also evaluated the influence of the initial concentration of $\mathrm{CuPc}$ on its degradation. The results are plotted in Figure 6, in which the curves represent the fraction of remaining contaminant $\left(C / C_{0}\right)$ obtained with pyrite nanoparticles (Figure 6a) or microparticles (Figure 6b). In both cases, the degradation proceeded much more quickly at lower levels of dye (nanoparticles: ca. 4 times; microparticles: ca. 2 times), corroborating previous reports of delayed degradation at higher dye concentrations [29]. Nevertheless, experiments with a relatively concentrated dye solution $(5 \mathrm{mg} / \mathrm{L})$ and low nanoparticle loading $(0.08 \mathrm{~g} / \mathrm{L})$ still gave a degradation efficiency of $17 \%$ within $20 \mathrm{~h}$.

The use of pyrite nanoparticles for CuPc degradation acidified the system. In the performed experiments, the $\mathrm{pH}$ usually attains a final value of the order of 4-5, where Fenton reaction is far more efficient. Consequently, special $\mathrm{pH}$ control is not required. This it shown in Figure 7, for experiments performed with two different concentration values of dye and pyrite nanoparticle loads.

a)

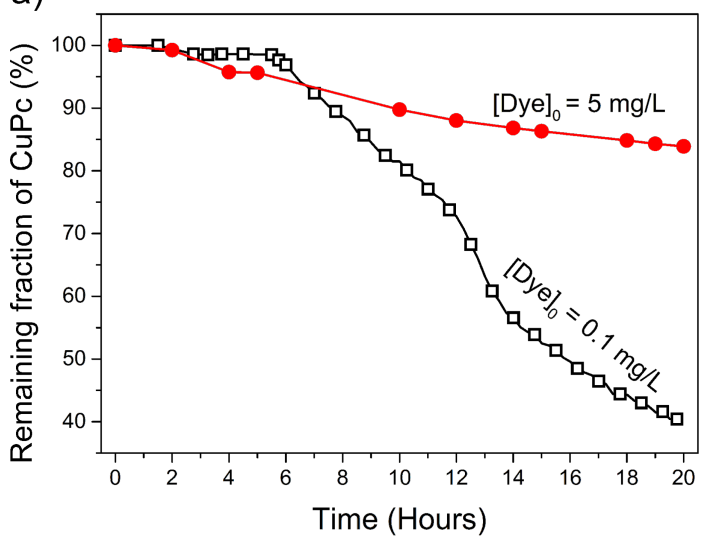

We used high performance liquid chromatography (HPLC) to identify byproducts generated during degradation. The chromatogram of unreacted dye was employed as control (Figure 8) and showed a single peak in the UV region with a retention time of 2.42 minutes. After $27 \mathrm{~h}$ of reaction with nanoparticles, the chromatogram exhibited seven new peaks (retention times: $1.56,3.01,3.56,4.24,5.71,6.31$ and 9.12 minutes, respectively) and an appreciable decrease in the intensity of peak corresponding to the dye (at 2.42 minutes). The peak at 5.71 minutes, which is associated with phthalamines, a diagnostic species for the oxidative destruction of phthalocyanines [30], showed a $\lambda_{\max }$ of $217 \mathrm{~nm}$.

\section{Discussion}

There have been previous reports on the surface generation of $\mathrm{H}_{2} \mathrm{O}_{2}$ upon oxidative dissolution of pyrite [7,8,10,12-14]. This reactivity, coupled with the iron delivery and the decrease in $\mathrm{pH}$ that occur upon dissolution of pyrite, are the reasons that this mineral is ideal for use in wastewater treatments. Furthermore, in the present work, we have demonstrated

b)

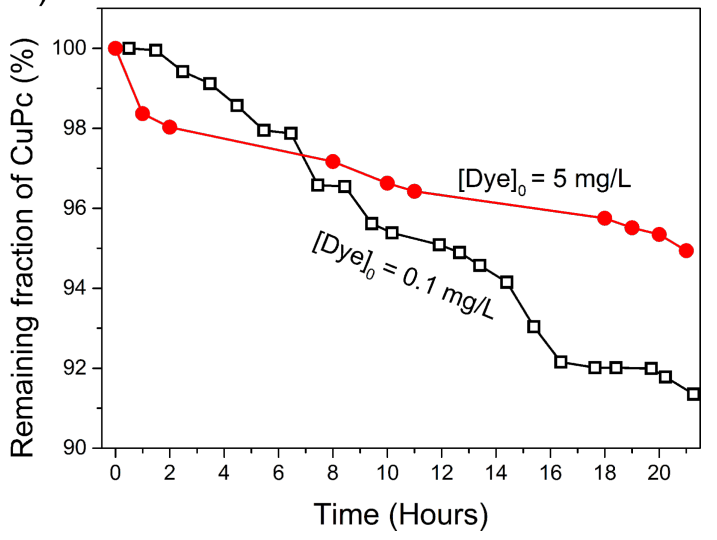

Figure 6: Decoloration rate at different initial concentrations of CuPc in suspensions of pyrite a) nanoparticles or b) microparticles, at loadings of $0.08 \mathrm{~g} / \mathrm{L}$.

a)

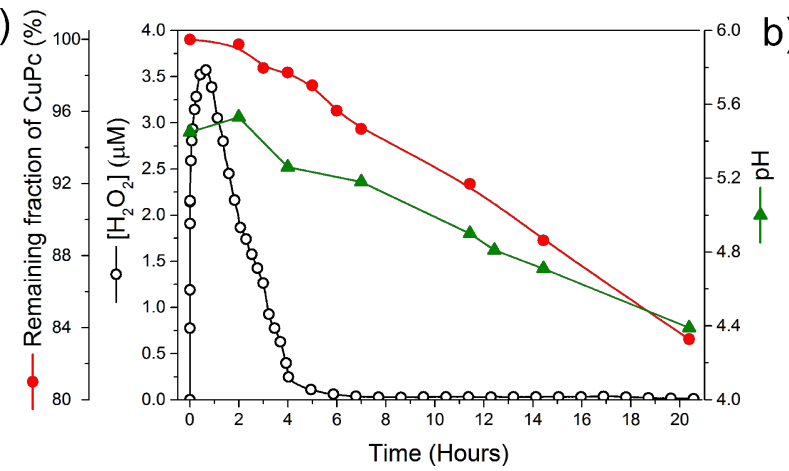

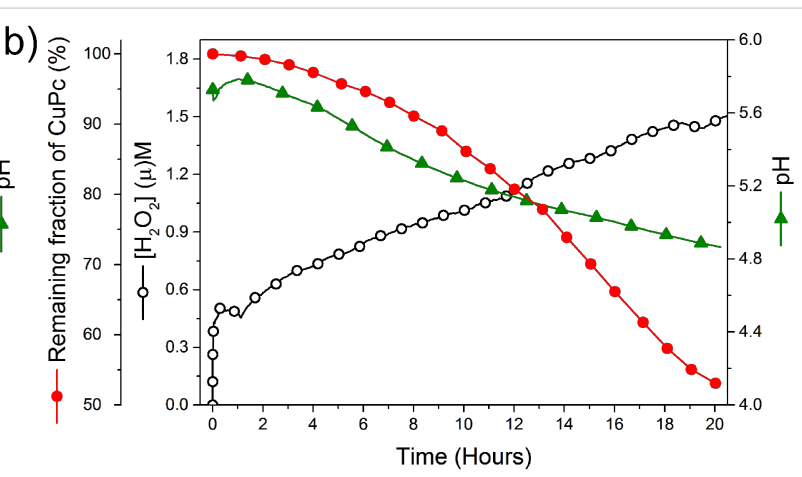

Figure 7: The $\mathrm{pH}$ and $\mathrm{H}_{2} \mathrm{O}_{2}$ evolution in CuPc solutions with pyrite nanoparticles (a) $[\mathrm{CuPc}]_{0}=5 \mathrm{mg} / \mathrm{L}$ at $0.06 \mathrm{~g} / \mathrm{L}$ loading (b) $[\mathrm{CuPc}]_{0}=0.1 \mathrm{mg} / \mathrm{L}$ at $0.04 \mathrm{~g} / \mathrm{L}$ loading. 


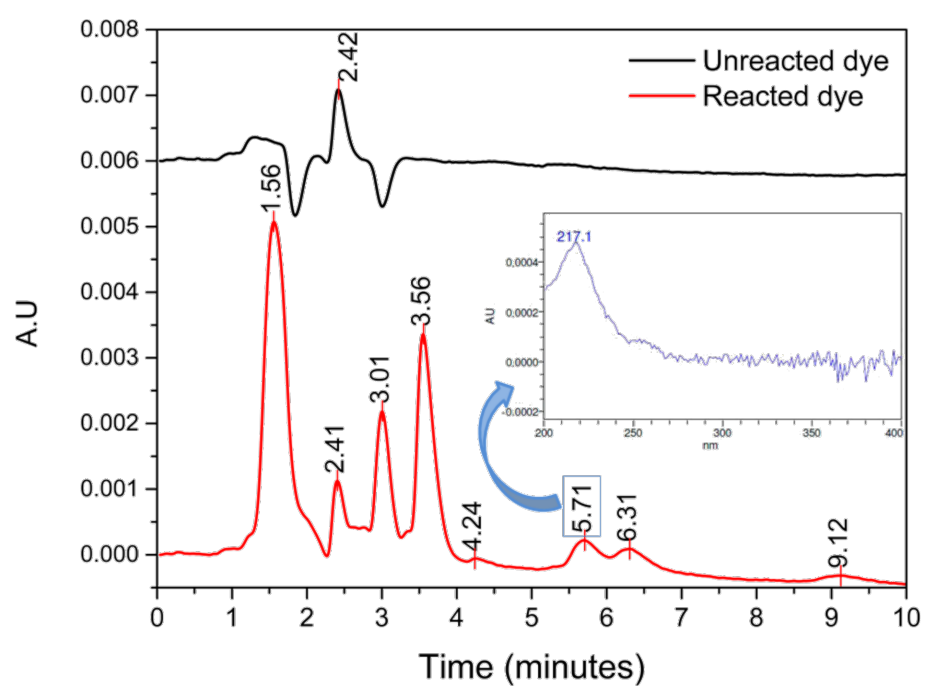

Figure 8: a) HPLC Chromatograms (UV detection: $219 \mathrm{~nm}$ ) of untreated dye, and of dye treated with suspensions of nanoparticles for $27 \mathrm{~h}$. b) UV-vis spectrum of the peak at 5.7 minutes $\left(\lambda_{\text {max }}: 217 \mathrm{~nm}\right)$.

the efficiency of pyrite at breaking down the ring of $\mathrm{CuPc}$, which we confirmed through the HPLC identification of sulfophthalimide, the most common oxidative byproduct of this dye [30]. Practical interest in pyrite as a Fentontype reagent depends on its capability to efficiently and sustainably generate $\mathrm{H}_{2} \mathrm{O}_{2}$ for oxidative degradation of contaminants. Figure 9 summarizes the proposed reaction mechanisms which are involved in the $\mathrm{H}_{2} \mathrm{O}_{2}$ generation and in the subsequent degradation of $\mathrm{CuPc}$ by the hydroxyl radical [29].
Although the mechanism of $\mathrm{H}_{2} \mathrm{O}_{2}$ generation remains controversial $[7,10-15,31,32]$, researchers agree that this product is afforded by reaction of iron defect sites at the pyrite surface with adsorbed oxygen and water, according to Equation 1 and Equation 2, below. This chemistry involves the intermediate generation of $\mathrm{O}_{2}{ }^{--}$from dissociative adsorption of $\mathrm{O}_{2(\mathrm{~g})}$ at the pyrite surface:

$$
\equiv \mathrm{pyFe}^{2+}+\mathrm{O}_{2(\mathrm{~g}) \text { ads }} \rightarrow \equiv \mathrm{pyFe}^{3+}+\mathrm{O}_{2}^{\cdot-}
$$

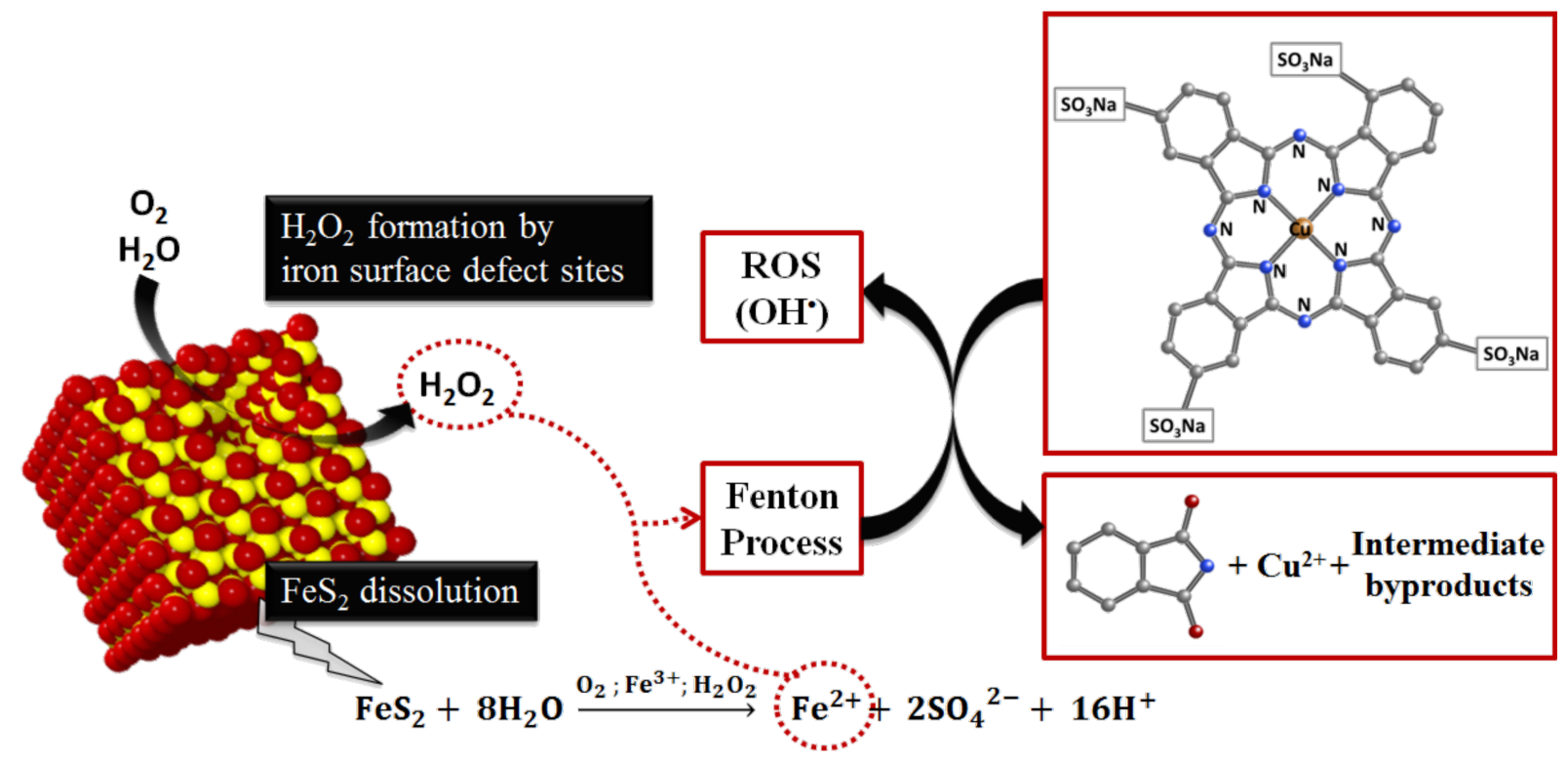

Figure 9: Proposed reaction mechanisms for the generation of $\mathrm{H}_{2} \mathrm{O}_{2}$ and for the oxidative degradation of $\mathrm{CuPc}$ by $\mathrm{OH}^{*}$. 


$$
\equiv \mathrm{pyFe}^{2+}+\mathrm{O}_{2}^{\bullet-}+2 \mathrm{H}^{+} \rightarrow \equiv \mathrm{pyFe}^{3+}+\mathrm{H}_{2} \mathrm{O}_{2} \text { ads }
$$

The adsorbed $\mathrm{H}_{2} \mathrm{O}_{2}$ is then released into the solution. Simultaneously, the amount of $\mathrm{Fe}^{2+}$ required for the Fenton reaction to occur is supplied to the solution by oxidative dissolution of pyrite in the presence of $\mathrm{O}_{2}(\mathrm{aq})$, according to Equation 3:

$$
2 \mathrm{FeS}+7 \mathrm{O}_{2(\mathrm{aq})}+\mathrm{H}_{2} \mathrm{O} \rightarrow 2 \mathrm{Fe}^{2+}+4 \mathrm{SO}_{4}^{2-}+4 \mathrm{H}^{+}
$$

At this moment, $\mathrm{Fe}^{2+}$ starts to catalyze the decomposition of $\mathrm{H}_{2} \mathrm{O}_{2}$ into $\mathrm{OH}^{\bullet}$ and other reactive oxygen species involved in the oxidation of organics pollutants, according to the Fenton chain-reaction sequence, described by Equations 4 to 7 , below [33].

$$
\begin{aligned}
& \mathrm{Fe}^{2+}+\mathrm{H}_{2} \mathrm{O}_{2} \rightarrow \mathrm{Fe}^{3+}+\mathrm{HO}^{-}+\mathrm{OH}^{\bullet} \\
& k_{1}=70 \mathrm{M}^{-1} \mathrm{~s}^{-1} \\
& \mathrm{Fe}^{3+}+\mathrm{H}_{2} \mathrm{O}_{2} \rightarrow \mathrm{Fe}-\mathrm{OOH}^{2+}+\mathrm{H}^{+} \\
& \begin{array}{l}
\mathrm{Fe}-\mathrm{OOH}^{2+} \rightarrow \mathrm{HOO}^{\bullet}+\mathrm{Fe}^{2+} \\
k_{5-6}=0.001-0.02 \mathrm{M}^{-1} \mathrm{~s}^{-1}
\end{array} \\
& 2 \mathrm{OOH}^{\bullet} \rightarrow \mathrm{O}_{2}+\mathrm{H}_{2} \mathrm{O} \\
& k_{7}=8.6 \times 10^{5} \mathrm{M}^{-1} \mathrm{~s}^{-1}
\end{aligned}
$$

In this sequence, Equation 5 and Equation 6 are the slowest and diminish the recycling between $\mathrm{Fe}^{2+}$ and $\mathrm{Fe}^{3+}$. Consequently, they form the rate-limiting step in the generation of free radical species and decrease the efficiency of the oxidative degradation of contaminants. When pyrite is used as iron source for heterogeneous catalysis, an additional mechanism for the $\mathrm{Fe}^{2+}$ regeneration occurs through Equation 8:

$$
\mathrm{FeS}_{2}+14 \mathrm{Fe}^{3+}+8 \mathrm{H}_{2} \mathrm{O} \rightarrow 15 \mathrm{Fe}^{2+}+16 \mathrm{H}^{+}+2 \mathrm{SO}_{4}^{2-}
$$

This drives the oxidation of pyrite by $\mathrm{Fe}^{3+}$, thereby releasing $\mathrm{Fe}^{2+}$ and consequently, accelerating the degradation of $\mathrm{H}_{2} \mathrm{O}_{2}$ through Equation 4. As shown above, Equation 3 and Equation 8 both release protons, promoting acidification simultaneously to the delivery of iron into solution.
The rate expressions associated to Equation 3 and Equation 8 are, respectively [28]:

$$
\operatorname{rate}\left(\mathrm{O}_{2}\right)=\mathrm{SA}\left(\frac{m}{m_{0}}\right)^{0.67} 10^{-8.1}\left[\mathrm{O}_{2}\right]^{0.5}\left[\mathrm{H}^{+}\right]^{-0.11}
$$

$$
\operatorname{rate}\left(\mathrm{Fe}^{3+}\right)=\mathrm{SA}\left(\frac{m}{m_{0}}\right)^{0.67} 10^{-6.07}\left[\mathrm{Fe}^{3+}\right]^{0.93}\left[\mathrm{Fe}^{2+}\right]^{-0.4}
$$

Both equations depend on the reactive surface, $\mathrm{SA}(1 / \mathrm{dm})$. Since $\mathrm{H}_{2} \mathrm{O}_{2}$ is also formed by reactions at the surface, the dye degradation efficiency is expected to increase with a greater surface area (i.e., smaller particles should give better results). We assessed this hypothesis by performing batch experiments to compare the degradation behavior of nanoparticles with that of microparticles (Figure 3 and Figure 4).

As expected, the nanoparticles gave strikingly better results than the microparticles. At low loading $(0.08 \mathrm{mg} / \mathrm{L})$ and $20 \mathrm{~h}$ reaction time, the former enabled $60 \% \mathrm{CuPc}$ removal, whereas the latter enabled only $7 \%$ removal. As such, the $\mathrm{H}_{2} \mathrm{O}_{2}$ was consumed far more quickly when nanoparticles were used. This can be explained by the fact that the greater surface area of the nanoparticles not only provides more sites for $\mathrm{H}_{2} \mathrm{O}_{2}$ generation, but also leads to faster oxidative dissolution of the pyrite itself, as this rate is proportional (in mass terms) to the reactive surface area. Thus, the nanoparticles rapidly supply the solution with iron, which induces the rapid transformation of $\mathrm{H}_{2} \mathrm{O}_{2}$ into $\mathrm{OH}^{\bullet}$ radicals, according to the Fenton reaction scheme. The dye concentration was indirectly proportional to the degradation rate (Figure 6), indicating that the best catalytic activities were reached by using dilution procedures that provide low concentrations of contaminant. Moreover, the system does not require a $\mathrm{pH}$ control to degrade $\mathrm{CuPc}$ (Figure 7).

\section{Conclusion}

We evaluated the use of synthetic pyrite nanoparticles and naturally derived pyrite microparticles for Fenton-like oxidative degradation of the dye $\mathrm{CuPc}$ as representative industrial contaminant. Since pyrite spontaneously and sustainably releases $\mathrm{H}_{2} \mathrm{O}_{2}$ upon surface reaction with adsorbed $\mathrm{O}_{2(\mathrm{~g})}$ and $\mathrm{H}_{2} \mathrm{O}$, it might prove invaluable for Fenton-like treatment of wastewater, obviating the need for external addition of $\mathrm{H}_{2} \mathrm{O}_{2}$. Furthermore, dissolution of pyrite in water promotes the recycling of $\mathrm{Fe}^{2+}$ into $\mathrm{Fe}^{3+}$ and vice versa, triggering Fenton production of $\mathrm{HO}^{\circ}$, the primary species responsible for oxidative degradation of the pollutant. Our results with the synthetic pyrite nanoparticles demonstrate that $\mathrm{H}_{2} \mathrm{O}_{2}$ is indeed generated by iron disulfide, in the absence of trace compounds founds in natural pyrite. 
Our kinetics analysis showed that the pyrite nanoparticles enabled a ca. 8 times greater efficiency of pollutant removal than did the microparticles. The use of synthetic pyrite nanoparticles avoids the dangers of heavy metal release that often occurs upon dissolution of naturally occurring (i.e., mineral derived) pyrites. Furthermore, the low required loadings of these nanoparticles make this procedure even more environmentally friendly. Lastly, since the process does not require UV-illumination or $\mathrm{pH}$ constraints, it may serve as a cheap alternative to conventional Fenton approaches for the selective oxidation of pollutant dyes.

\section{Experimental Chemicals}

Copper phthalocyanine-3, 4', 4"', 4"' - tetrasulfonic acid tetrasodium salt (85\%), oleylamine (OA, 70\%), sulfur (99.99\%) and toluene (99.8\% anhydrous) were purchased from Sigma Aldrich. Ferrous chloride tetrahydrate $\left(\mathrm{FeCl}_{2} \cdot 4 \mathrm{H}_{2} \mathrm{O}, 99 \%\right)$ was purchased from Fluka. Absolute ethanol was purchased from Quimivita. All chemicals were used as received without any further purification. Aqueous suspensions of pyrite were prepared using deionized water (resistivity: ca. $18 \mathrm{M} \Omega \cdot \mathrm{cm}$ ) purified in a Milli-Q system at an initial $\mathrm{pH}$ of about 5.5 .

\section{Synthesis of pyrite nanoparticles}

Pyrite nanocrystals were synthesized by the hot injection method [26,34]. The experiments were performed in a threeneck flask connected to a reflux condenser. The device was heated by an electric mantle temperature-probe controlled. Sulfur and $\mathrm{FeCl}_{2} \cdot 4 \mathrm{H}_{2} \mathrm{O}$ were used as starting materials. Briefly, $0.4 \mathrm{mmol}$ of $\mathrm{FeCl}_{2} \cdot 4 \mathrm{H}_{2} \mathrm{O}$ were dehydrated and dissolved in $6 \mathrm{~mL}$ of $\mathrm{OA}$ under $\mathrm{N}_{2}$ atmosphere. The resulting solution was maintained at $100{ }^{\circ} \mathrm{C}$ for $1 \mathrm{~h}$, until an $\mathrm{Fe}-\mathrm{OA}$ complex was formed. A solution of $2.4 \mathrm{mmol}$ of sulfur in $6 \mathrm{~mL}$ of $\mathrm{OA}$ (to achieve an $\mathrm{Fe} / \mathrm{S}$ molar ratio of 1:6) was injected, heated to $220^{\circ} \mathrm{C}$ and allowed to react for $20 \mathrm{~min}$. The mixed solution was cooled to room temperature. Nanocrystals were dispersed and separated by centrifugation and re-dissolving with several aliquots of a 1:1 toluene/ethanol solution.

\section{Preparation of pyrite microparticles}

Natural pyrite cubes (Logroño, Spain) were milled using a diamond disk and sieved $(63 \mu \mathrm{m})$ to obtain pyrite powder. The resulting particles presented an average diameter of $1.4 \mu \mathrm{m}$ (laser diffraction particle size analyzer, LS13320) and a specific surface area (BET) of $1.46 \mathrm{~m}^{2} / \mathrm{g}$. Prior to use, the pyrite samples were cleaned by sonication in ethanol $(96 \%), \mathrm{HCl}(0.25 \mathrm{M})$ and deoxygenated water, and then dried under vacuum, purged with $\mathrm{N}_{2}$ and finally, stored in a glove box $\left(\mathrm{N}_{2}\right.$ atmosphere) until use.

\section{Characterization}

The nanoparticles were characterized by high-resolution transmission electron microscopy (HR-TEM), selected area electron diffraction (SAED) and X-ray diffraction (XRD). The TEM studies were done on a JEOL JEM-3011 microscope with accelerating voltage of $200 \mathrm{kV}$. The XRD analysis of the nanoparticles and the microparticles was done on a Philips diffractometer with a graphite monochromator and $\mathrm{Cu} \mathrm{K} \alpha$ radiation $(1.54 \AA)$. Indexing of pyrite reflections were done using the JCPDS 00-042-1340 card ( $\mathrm{FeS}_{2}$ [pyrite]). Further, Rietveld refinements were performed to rule out the presence of other crystalline iron sulfides (e.g., marcasite, pyrrhotite and troilite) and to calculate the average values of crystallite size and microstrain (according to the Scherrer method [35]).

\section{Experimental set-up}

Kinetic experiments were conducted in stirred glass reactors under ambient conditions (i.e., open to atmosphere and at room temperature $\left[22 \pm 2{ }^{\circ} \mathrm{C}\right]$; K-type thermocouple). Pyrite powder was deposited onto silicone strips as a thin film of particles, and the strips were then adhered to the inner reactor walls. The $\mathrm{pH}$ was monitored by a glass pH-meter (Vernier FPH-BTA) with an $\mathrm{Ag} / \mathrm{AgCl}$ reference electrode.

The temporal change in the $\mathrm{H}_{2} \mathrm{O}_{2}$ concentration in solution was monitored by an amperometric microsensor (ISO-HPO-100, World Precision Instruments, Inc.). These sensors contain a flexible, activated carbon-fiber sensing electrode coated with a proprietary membrane that enhances the low detection limit (LDL) of $\mathrm{H}_{2} \mathrm{O}_{2}$ to a value of $10 \mathrm{nM}$ (ten times lower than in the bare Pt electrode; LDL: $0.1 \mu \mathrm{M}$ ) with a response time of less than $5 \mathrm{~s}$. The signal was amplified with a picoamperemeter (Apollo 4000 Free Radical Analyzer, World Precision Instruments). Measurements were taken by using a polarization voltage of $0.4 \mathrm{~V}$ versus an $\mathrm{Ag} / \mathrm{AgCl}$ reference electrode.

Simultaneous to $\mathrm{H}_{2} \mathrm{O}_{2}$ generation, the decoloration (degradation) of $\mathrm{CuPc}$ was monitored by tracking the absorbance at $630 \mathrm{~nm}$, using fiber optic UV-vis spectrometry (Black-comet, Stellarnet). A liquid waveguide capillary flow cell (LWCC; path length: $250 \mathrm{~cm}$; WPI), was connected to the batch reactor by a peristaltic pump (masterflex pump system, Cole-Parner Instrument Co; see Figure 10). Alternatively, when the initial dye concentration was too high (i.e. when it led to saturation in the Vis spectra obtained with the LWCC), a standard quartz cuvette (path length: $1 \mathrm{~cm}$ ) was used and the decoloration of the dye was done measuring aliquots at different times of the process.

The degradation of CuPc was analyzed by high performance liquid chromatography (HPLC; Waters Alliance 2975 equipped 


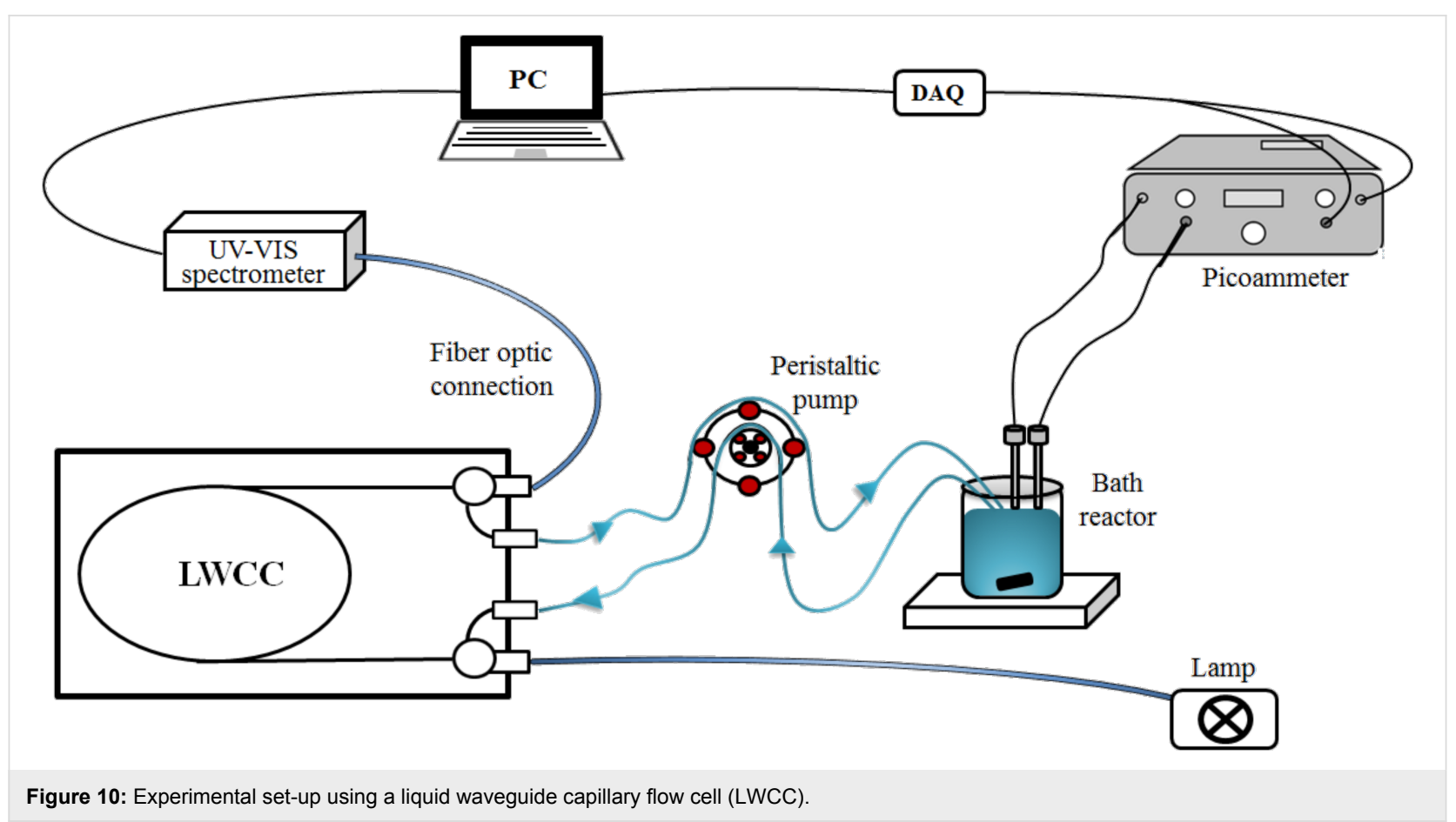

with a Waters 996 Photodiode Array Detector; UV-vis detection), using a C8 column (Waters Symmetry: $150 \times 4.6 \mathrm{~mm}$, $3.5 \mu \mathrm{m})$. The mobile phases were $0.1 \%$ aq phosphoric acid (A), and acetonitrile (B), run in a linear gradient $(80: 20, \mathrm{v} / \mathrm{v})$ at a flow rate of $1 \mathrm{~mL} / \mathrm{min}$.

\section{Acknowledgements}

This research was funded by the Spanish Ministry of Science and Innovation as part of the MICINN-FEDER Project CGL2011-30079. The authors would like to thank doctoral student Ruth Otero Lorenzo (Department of Applied Physics, University of Vigo), for her help and advice in the synthesis of pyrite nanoparticles, and Dr. José Benito Rodríguez (C.A.C.T.I. research institute), for his help in the HR-TEM analyses.

Finally, we thank the anonymous referees for their thorough review and highly appreciate the comments and suggestions, which significantly contributed to improving the quality of the publication.

\section{References}

1. Garrido-Ramírez, E. G.; Theng, B. K. G.; Mora, M. L. Appl. Clay Sci. 2010, 47, 182-192. doi:10.1016/j.clay.2009.11.044

2. Kamat, P. V.; Meisel, D. C. R. Chim. 2003, 6, 999-1007. doi:10.1016/j.crci.2003.06.005

3. Valdés-Solís, T.; Valle-Vigón, P.; Álvarez, S.; Marbán, G.; Fuertes, A. B. Catal. Commun. 2007, 8, 2037-2042. doi:10.1016/j.catcom.2007.03.030

4. Andreozzi, R.; Caprio, V.; Insola, A.; Marotta, R. Catal. Today 1999, 53, 51-59. doi:10.1016/S0920-5861(99)00102-9
5. Farhataziz; Ross, A. B. Hydroxyl Radical and Perhydroxyl Radical and Their Radical lons. In Selected Specific Rates of Reactions of Transients from Water in Aqueous Solution; Anbar, M., Ed.; Nat. Stand. Ref. Data Ser., Nat. Bur. Stand. (U.S.), Vol. 59; U.S. Government Printing Office: Washington, DC, USA, 1977.

6. Walling, C. Acc. Chem. Res. 1975, 8, 125-131. doi:10.1021/ar50088a003

7. Borda, J. M.; Elsetinow, R. A.; Strongin, R. D.; Schoonen, M. A. Geochim. Cosmochim. Acta 2003, 67, 935-939. doi:10.1016/S0016-7037(02)01222-X

8. Cohn, C. A.; Mueller, S.; Wimmer, E.; Leifer, N.; Greenbaum, S.; Strongin, D.; Schoonen, M. A. A. Geochem. Trans. 2006, 7, No. 3. doi:10.1186/1467-4866-7-3

9. Gournis, D.; Karakassides, M. A.; Petridis, D. Phys. Chem. Miner. 2002, 29, 155-158. doi:10.1007/s002690100215

10. Javadi Nooshabadi, A.; Larsson, A.-C.; Kota, H. R. Miner. Eng. 2013, 49, 128-134. doi:10.1016/j.mineng.2013.05.016

11. Javadi Nooshabadi, A.; Hanumantha Rao, K. Hydrometallurgy 2014, 141, 82-88. doi:10.1016/j.hydromet.2013.10.011

12. Schoonen, M. A. A.; Harrington, A. D.; Laffers, R.; Strongin, D. R. Geochim. Cosmochim. Acta 2010, 74, 4971-4987. doi:10.1016/j.gca.2010.05.028

13. Xu, J.; Sahai, N.; Eggleston, C. M.; Schoonen, M. A. A. Earth Planet. Sci. Lett. 2013, 363, 156-167. doi:10.1016/j.epsl.2012.12.008

14. Davila, A. F.; Fairén, A. G.; Gago-Duport, L.; Stoker, C.; Amils, R.; Bonaccorsi, R.; Zavaleta, J.; Lim, D.; Schulze-Makuch, D. McKay, C. P. Earth Planet. Sci. Lett. 2008, 272, 456-463. doi:10.1016/j.epsl.2008.05.015

15. Wang, W.; Qu, Y.; Yang, B.; Liu, X.; Su, W. Chemosphere 2012, 86, 376-382. doi:10.1016/j.chemosphere.2011.10.026

16. Arienzo, M. Chemosphere 1999, 39, 1629-1638. doi:10.1016/S0045-6535(99)00061-2 
17. Matta, R.; Hanna, K.; Chiron, S. Sci. Total Environ. 2007, 385, 242-251. doi:10.1016/j.scitotenv.2007.06.030

18. Che, H.; Lee, W. Chemosphere 2011, 82, 1103-1108. doi:10.1016/j.chemosphere.2010.12.002

19. Bae, S.; Kim, D.; Lee, W. Appl. Catal., B: Environ. 2013, 134-135, 93-102. doi:10.1016/j.apcatb.2012.12.031

20. Li, M.-L.; Yao, Q.-Z.; Zhou, G.-T.; Qu, X.-F.; Mu, C.-F.; Fu, S.-Q. CrystEngComm 2011, 13, 5936-5942. doi:10.1039/c1ce05478c

21. Lucas, J. M.; Tuan, C.-C.; Lounis, S. D.; Britt, D. K.; Qiao, R.; Yang, W.; Lanzara, A.; Alivisatos, A. P. Chem. Mater. 2013, 25, 1615-1620. doi:10.1021/cm304152b

22. Bai, Y.; Yeom, J.; Yang, M.; Cha, S.-H.; Sun, K.; Kotov, N. A. J. Phys. Chem. C 2013, 117, 2567-2573. doi:10.1021/jp3111106

23. Xuefeng, Q.; Yi, X.; Yitai, Q. Mater. Lett. 2001, 48, 109-111. doi:10.1016/S0167-577X(00)00288-3

24. Kar, S.; Chaudhuri, S. Chem. Phys. Lett. 2004, 398, 22-26. doi:10.1016/j.cplett.2004.09.028

25. Wang, D.-W.; Wang, Q.-H.; Wang, T.-M. CrystEngComm 2010, 12, 755-761. doi:10.1039/b917941k

26. Li, W.; Döblinger, M.; Vaneski, A.; Rogach, A. L.; Jäckel, F.; Feldmann, J. J. Mater. Chem. 2011, 21, 17946-17952. doi:10.1039/c1jm13336e

27. Parkhurst D. L.; Appelo C. A. J. User's guide to PHREEQC (Version 2); Water-Resources Investigations Report 99-4259; U.S. Geological Survey Publications, 1999

28. Williamson, M. A.; Rimstidt, J. D. Geochim. Cosmochim. Acta 1994, 58, 5443-5454. doi:10.1016/0016-7037(94)90241-0

29. Shu, H.-Y.; Chang, M.-C. J. Hazard. Mater. 2005, 125, 96-101. doi:10.1016/j.jhazmat.2005.05.016

30. Matthews, R. D. Transformation and Decolorization of Reactive Phthalocyanine Dyes. Ph.D. Thesis, Georgia Institute of Technology, Atlanta, GA, USA, 2003.

31. Jones, G. C.; van Hille, R. P.; Harrison, S. T. L. Appl. Microbiol. Biotechnol. 2013, 97, 2735-2742. doi:10.1007/s00253-012-4116-y

32. Weerasooriya, R.; Makehelwala, M.; Bandara, A. Colloids Surf., A 2010, 367, 65-69. doi:10.1016/j.colsurfa.2010.06.023

33. Navalon, S.; Alvaro, M.; Garcia, H. Appl. Catal., B: Environ. 2010, 99 1-26. doi:10.1016/j.apcatb.2010.07.006

34. Lin, Y.-Y.; Wang, D.-Y.; Yen, H.-C.; Chen, H.-L.; Chen, C.-C.; Chen, C.-M.; Tang, C.-Y.; Chen, C.-W. Nanotechnology 2009, 20, 405207. doi:10.1088/0957-4484/20/40/405207

35. Scherrer, P. Nachr. Ges. Wiss. Goettingen, Math.-Phys. KI. 1918, 26, 98-100.

http://www.digizeitschriften.de/dms/resolveppn/?PPN=GDZPPN002505 $\underline{045}$

\section{License and Terms}

This is an Open Access article under the terms of the Creative Commons Attribution License

(http://creativecommons.org/licenses/by/2.0), which permits unrestricted use, distribution, and reproduction in any medium, provided the original work is properly cited.

The license is subject to the Beilstein Journal of Nanotechnology terms and conditions: (http://www.beilstein-journals.org/bjnano)

The definitive version of this article is the electronic one which can be found at:

doi:10.3762/bjnano.5.97 